\title{
O LEGADO DOS MOVIMENTOS SOCIAIS DOS ANOS 70-80*
}

\author{
Ricardo de Jesus Silveira
}

O que pretendo com este texto é destacar o que os movimentos sociais dos anos 70-80 legaram à sociedade brasileira como experiência inédita e de fundamental importância à constituição de uma sociedade verdadeiramente democrática. $\mathrm{O}$ objetivo dessa abordagem é menos contrariar algumas análises que me parecem depreciativas e equivocadas dos movimentos e mais realçar a importância daquilo que os movimentos nos deixaram para o enfrentamento dos problemas que nos traz a globalização econômica, de modelo neoliberal, entre os quais, o problema do desemprego e o da exclusão social. Como se sabe, a urgência no tratamento dessa questão tende a facilitar ações apressadas, imediatistas e certamente paliativas. E, com efeito, tende-se a desconsiderar os caminhos abertos pelos movimentos que, assim me parecem, são os mais apropriados para enfrentarmos um futuro que se coloca diante de nós de maneira imprevisível quanto às possibilidades de construirmos uma sociabilidade minimamente civilizada.

Nos últimos trinta anos vivemos a experiência de um regime autoritário de governo e a sua superação com a passagem para um regime de democracia representativa. Nessa mudança de regime político, que culminou com a Carta Constitucional de 1988, os movimentos sociais foram, sem dúvida, os grandes atores desse processo que se caracterizou simultaneamente como resistência e negação à ordem autoritária e como proposição e instituição de uma ordem democrática fundada no reconhecimento dos direitos de cidadania.

Ora, isso não foi nada pouco para ser desconsiderado. Se tomarmos a Constituição de 1988 como o coroamento desse processo, no qual os movimentos sociais ocuparam a cena pública, vamos perceber

\footnotetext{
" Versão da palestra proferida pelo autor. (N. da C.E.)
} 
que os valores democráticos, nela inscritos, são inéditos como experiência de sociedade e não seria exagero dizer que a sociedade brasileira de antes de 1964 não se reconheceria na Carta de 1988, o que eqüivale a dizer que o processo vivido nesses anos recentes logrou estabelecer os fundamentos de uma nova sociedade, marcada, especialmente, pelo reconhecimento dos direitos de cidadania que a sociedade passou a atribuir-se através dos seus movimentos.

De fato, foi como o surgimento de uma nova sociedade, uma sociedade que, em face dos constrangimentos à vida social e política impostos pelo regime militar, soube criar novos espaços de interlocução públicos, revelando uma capacidade política da qual se tinham dúvidas e mostrando-se portadora de princípios e valores democráticos impensados como experiência histórica.

Não obstante, nestes anos 90, muitos pesquisadores e militantes de movimentos sociais' têm acusado, de um modo geral, um certo refluxo dos movimentos (e aqui penso, especialmente, naqueles motivados por melhores condições de vida urbana), dando-nos a entender, com a diminuição da incidência dos movimentos, que houve uma abdicação das conquistas políticas dos anos 80 ou que o fervor democrático verificado nos anos anteriores tivesse, de súbito, desaparecido, o que poderia ser reforçado pelo fato de também se verificar uma baixa participação da sociedade civil nos espaços de interlocução públicos que foram criados como resultado da experiência daqueles anos. ${ }^{2}$

Certamente, trata-se de uma questão polêmica que merece uma análise cuidadosa, sobretudo porque pode nos levar a desconsiderar o imenso avanço quanto à organização política da sociedade civil, jamais antes alcançado pela sociedade brasileira, e, assim, pôr a perder o que os movimentos, nesses poucos, mas intensos anos de lutas, nos legaram como rica experiência de vida pública participativa.

Não discutiria a diminuição da incidência dos movimentos, mas essa constatação deveria ser considerada a partir do que me parece uma evidência lógica: a de que os anos 90 se configuram como uma conjuntura distinta da anterior, mais ainda, como produto dela, e, como tal, o refluxo dos movimentos deve ser considerado como indicação de conquistas realizadas e da afirmação de um novo tempo e jamais, porque impróprio, como um abandono, pela população, dos valores e princípios democráticos tão fantasticamente afirmados como discurso e como prática dos anos anteriores. 
A diminuição do número de movimentos nos anos 90 não deve ser tomada como indicador de debilidade. Esta, menos pelo caráter efêmero e intermitente que marca os movimentos populares, poderia ser dada pela forma anacrônica de sua organização verticalizada, centralizada e antidemocrática, pretensamente de vanguarda, mas que, longe de aglutinar e integrar os setores populares, afasta-os do processo de lutas, e toma o seu lugar, como razão iluminada, mas que se revela insensível à demanda de participação que se registrou nos setores populares urbanos nos anos 80 - uma forma de organização que, apesar de superada pela maioria dos movimentos recentes, ainda não foi de todo apagada da memória nem da prática de muitos grupos e lideranças que se consideram os eleitos pela história, com a "missão" de impor a todas as demais categorias e classes o "único e real" projeto histórico de uma verdadeira democracia. ${ }^{3}$

Assim considerando, indicar o refluxo dos movimentos pela constatação de sua pouca visibilidade e fundado na consideração de uma nova conjuntura política, marcada por uma nova forma da luta de classes e lugar de conflito, assinalando a entrada em cena de novos atores, como as ONGs, por exemplo, corresponde, apenas, ao registro descritivo, perfeitamente plausível e congruente com aquilo que os movimentos nos legaram, ou seja: novos espaços de interlocução públicos, o que não é nada pouco, volto a dizer, pois é nesses espaços que se pode abrigar a pluralidade dos atores e coletivamente construir a democracia.

Tentar desqualificar esse processo de conquista de direitos e de uma noção de cidadania construída a partir da ação coletiva, ${ }^{4}$ reduzindoo à evidência quantitativa dos movimentos, o que faria supor, considerando sua menor visibilidade pública nos anos 90 , o fracasso de todo o processo anterior, corresponde a uma abordagem estéril, deslocada no tempo e, talvez por isso mesmo, antidemocrática, antipolítica, especialmente quando essa desqualificação ocorre para sair em defesa de um marxismo que, certamente, o próprio Marx, cuja genialidade deve ser sempre celebrada, ajudaria a enterrar. E aqui falo daquelas abordagens que ainda celebram o Marx de A questão judaica, cuja crítica dos direitos não abole apenas a idéia de cidadania liberal, mas a própria dimensão simbólica da cidadania, como "idéia-força", e, sem dúvida, também como história - conquistas que nos legaram os movimentos sociais em mais de dois séculos de lutas. ${ }^{5}$ 
Penso, assim, que é possível considerar não ter havido uma diminuição da participação, ou, que a diminuição dos movimentos não foi acompanhada de menos participação. Aprofundar essa discussão seria interessante mas demandaria muito mais tempo do que o reservado aqui, pois trata-se de uma posição que nos leva a uma discussão conceitual dos movimentos, porque depende de como se compreende o projeto neles inscrito, seus objetivos, sua cultura política, sua organização e, portanto, depende da maneira como se olha para os movimentos e os aceita como força social e política que, por si mesma, diz a que veio, não dependendo de nenhum juízo prévio para avaliar positiva ou negativamente sua potencialidade transformadora. E isso não é, por certo, uma discussão fácil e, muito menos, breve.

Creio, no entanto, que alguns questionamentos podem ser feitos para melhor corroborar a posição aqui defendida; por exemplo: se comparamos a participação atual com a ocorrida em outro momento histórico que não o dos anos 80 , talvez venhamos a considerar que a participação nos anos 90 é muito significativa do ponto de vista democrático; o que estou sugerindo é que um certo distanciamento e a consideração de um tempo histórico mais amplo favorecem uma análise mais consequiente com relação ao processo histórico e ao significado dos movimentos. Mas, há mais nessa questão além desse distanciamento que favorece uma leitura mais rica do objeto: para que o todo não seja reduzido à parte, também há que se atentar para o fato de não se poder generalizar para a sociedade como um todo processos que muitas vezes são particularmente observados em algum setor específico ou localidade. O caráter da diversidade social não pode ser nunca ignorado na análise, pois trata-se de um elemento de fundamental relevância à investigação que, entre outras questões, diz respeito à nossa cultura política, a qual não pode ser reduzida a qualquer manifestação particular.

Ademais, se considerarmos que a importância da discussão está no fato de termos como pressuposto que a presença de movimentos sociais na cena pública é indicador de maior participação política e, portanto, da prática democrática, um complicador para essa discussão seria observarmos a questão da saúde. No meu modo de ver, o setor da saúde no Brasil foi o que mais avançou no que tange à organização democrática, especialmente com a instituição do Sistema Único de Saúde (SUS), que significa a universalização do serviço de saúde para toda a população, indistintamente. Mas esse avanço na organização demo-

Rev. Mediações, Londrina, v. 5, n. 1, p. 79-94, jan./jun. 2000 
crática dos serviços de saúde não garante, por si só, o exercício desse direito conquistado pelos movimentos sociais.

Em Londrina, por exemplo, a participação na criação e gestão das políticas de saúde tem crescido, significativamente, nos anos 90 (pelo menos até 1998). Para termos uma idéia, de 1989 para cá, já foram realizadas cinco conferências de saúde. As duas últimas conferências tiveram uma participação média de mais de 500 pessoas, entre delegados, convidados e observadores (os delegados com direito a voto somam 320). O Conselho Municipal de Saúde está em pleno funcionamento, com representação de usuários, prestadores de serviço, trabalhadores da saúde e gestor. ${ }^{6}$ Portanto, em Londrina, não se poderia dizer que não há participação da sociedade civil no setor da saúde. Não obstante, talvez nesta cidade menos que em outras, é notório que os serviços de saúde são uma calamidade - conforme nos dão conta as freqüentes reportagens jornalísticas. E isso quer dizer que apesar da formalização constitucional do direito à saúde, nós somos incapazes de universalizálo na prática. Essa é a questão que, me parece, deve pautar a discussão sobre a capacidade sociopolítica transformadora dos movimentos e não sua maior ou menor visibilidade pública contestadora.

Nossa incapacidade de tornar prática a equivalência jurídica mostra-se ainda mais assustadora neste final de século com o processo de globalização econômica que, associado às políticas neoliberais, "pinta-nos" um quadro de exclusão de grande parte da população, ou melhor, de desfiliação conforme Castel (1998), marcado pelo desemprego e pela perda de direitos sociais, o que implica não apenas a incerteza quanto ao trabalho, mas também quanto à educação, à saúde $\mathrm{e}$, portanto, quanto às possibilidades de uma vida digna. Trata-se de um quadro terrível que não apenas nega lugar a muitos dos que estão chegando ao mercado de trabalho como expulsa muitos dos que já estão nele empregados.

Devemos notar que não é nada fácil, além de ser urgente, a solução dos problemas sociais, pois, junto a este quadro de exclusão associa-se a debilidade de um Estado necrosado em suas instituições, marcado pelo clientelismo e pela corrupção na gestão pública. Há, e não se pode deixar de, aqui, fazer referência, como que uma cultura patrimonial que atravessa não apenas o Estado, mas também a sociedade, e que tem raízes no colonialismo, marcando-nos como que gado com ferro; coisa indelével, sempre recorrente como explicação e como fato, 
e que nos impede perceber a distinção entre público e privado, lançando dúvidas sobre a validade da ordem, já que se vive no país do "jeitinho", onde mais bem sucedidos são os que transgridem a legalidade por opção de escolha, por vantagem. (E estão aí os exemplos de inúmeros escândalos de governos municipais, estaduais e federal, nestes anos 90 , sem qualquer punição.) As dificuldades são, de fato, imensas para se pensar uma sociedade de homens livres e iguais.

Com efeito, rememorar os movimentos dos anos 70-80 naquilo que eles nos legaram como conquista democrática parece-me importante como ponto de partida de uma reflexão necessária para o enfrentamento dessa realidade que se coloca diante de nós de maneira perversa, e cuja superação, assim me parece, só pode ser dada nos marcos de uma prática efetivamente democrática.

\section{OS MOVIMENTOS POPULARES DE LONDRINA NOS ANOS 80}

Aproveito a oportunidade para, nesta contribuição muito modesta que aqui faço sobre os movimentos sociais, fazer referência aos movimentos populares de Londrina que, me parecem, são muito ilustrativos para a argumentação que estou desenvolvendo, bem como exemplares do que foi, em quase todo o Brasil, a rica experiência dos movimentos populares nos anos de superação do regime autoritário.

Nesse sentido, os movimentos em Londrina são exemplares como sujeitos de uma experiência de sociedade em que a participação popular se impôs na cena pública. Estruturados nos locais de moradia em torno de questões relativas à satisfação das necessidades básicas de reprodução social, os movimentos populares locais foram além do protesto contra as más condições de vida e além da reivindicação por melhorias urbanas; ousaram questionar a ordem pública instituída e controlada por uma elite conservadora que, jamais, em tempo algum da história local, reconheceu nos segmentos populares a condição de sujeitos no partilhar a cidade.?

De mero objeto das eventuais políticas públicas, os setores populares, através dos seus movimentos, fizeram-se reconhecer e representar em novos espaços de negociação que se abriram, justamente, para abrigar os novos atores sociais e políticos que surgiam na cena pública por conta de sua ação organizada e contestadora da ordem vigente. 
No contexto local, o movimento da União Geral dos Moradores (UGM) é, certamente, o melhor exemplo dos movimentos locais dos anos 80. Como movimento de resistência às condições opressivas vividas pela população da periferia da cidade, a UGM foi além do protesto contra as más condições de vida, tornando-se um dos atores fundamentais de um momento de mudança democrática na história da cidade. Liderada por militantes das Comunidades Eclesiais de Base, Pastorais e Círculos Bíblicos, no início dos anos 80, a primeira bandeira de luta da UGM foi contra os constantes reajustes das prestações das casas populares alienadas ao BNH, sobre os quais não havia qualquer controle por parte dos mutuários, bandeira também de resistência às ameaças de despejo dos moradores com prestações atrasadas e também contra a inscrição dos seus respectivos nomes no Serviço de Proteção ao Crédito (SEPROC).

Numa conjuntura recessiva, em que se assinalava um elevado nível de desemprego, a ameaça de perda da casa e o corte de crédito era o que de pior poderia ocorrer à população da periferia. Foi nesse contexto e com essa bandeira de luta que, em junho de 1984, os moradores realizaram uma passeata — dos conjuntos populares da região norte até a $\mathrm{COHAB}$, no centro da cidade —, percorrendo $11 \mathrm{~km}$, com a finalidade de forçar a abertura de negociações com o poder público local para dar solução ao problema que viviam.

A esperada reação das "autoridades" públicas, em face da ousadia dos setores populares em querer alterar as regras contratuais, de mercado, foi, inicialmente, a de buscar minimizar e desqualificar a mobilização ocorrida, e protelar a solução do que era demandado. Todavia, não vendo atendidas suas reivindicações, o movimento realizou, um mês após a passeata, um acampamento em frente à Prefeitura Municipal, por onze dias, feito que não foi apenas amplamente divulgado pelos meios de comunicação, mas sobre o qual houve posicionamento sensível da imprensa em ralação às demandas populares, então ampliadas em relação às reivindicações da passeata, às quais se acrescentavam as relativas à saúde, ao emprego e, principalmente, ao transporte coletivo.

A favorável repercussão obtida com o acampamento junto à população e o conseqüiente desgaste do governo local foi, certamente, o que fez com que o poder público local abandonasse sua posição de intransigência e abrisse negociações com o movimento para dar solução aos problemas. Foi um desfecho que mostrou a ação popular como claramente vitoriosa, e esse entendimento se reafirmaria com a conquista 
mais importante que se poderia registrar com o acampamento: o despertar da opinião pública em favor dos acampados e a rede de solidariedade criada em torno deles por várias entidades e movimentos que passaram, a partir daquele momento, a denunciar com mais vigor as injustiças sociais e a se posicionar com mais ênfase e mais visibilidade sobre os problemas vividos pela cidade, apresentando soluções alternativas para diversas questões relativas à saúde, ao saneamento etc., que exigiam respostas rápidas e fundamentadas do poder público local, forçando, dessa forma, a participação na gestão da cidade, num evidente processo de politização das questões sociais.

Deve-se notar que todo esse processo de lutas para conquistar o direito de uma vida mais digna em meio urbano não foi pacífico; pelo contrário, a passeata e o acampamento foram ações tensas que provocaram reações igualmente tensas e autoritárias, com ameaças de prisões de lideranças e o impedimento policial das manifestações, mas o acirramento mais exacerbado desse processo de lutas só ocorreria, de fato, com a luta dos transportes coletivos, ocorrida seis meses após o acampamento. Durante todo o segundo semestre de 1984, após o desfecho vitorioso do acampamento, a UGM mobilizou e organizou os moradores para a luta por melhores condições no transporte coletivo da cidade. Reivindicavam-se mais linhas, mais ônibus e, principalmente, a participação dos usuários na gestão dos serviços, com o controle dos custos e, consequientemente, da tarifa.

A rigor, o movimento dos transportes realizado pela UGM representou o máximo de ousadia para a cidade. Pela primeira vez punhase em questão o caráter social da concessão de um serviço público. E isso significava submeter o capital privado ao interesse público, o que era, evidentemente, uma afronta àqueles que se julgavam autoridades morais, detentoras de um passado e um saber ao qual a cidade devia submeter-se, o que era principalmente uma afronta ao capitalista: ter que abrir sua empresa de ônibus ao controle do usuário do transporte — algo jamais imaginado, até então.

Frustradas todas as tentativas de abrir negociações com o poder público, o que foi tentado durante o segundo semestre de 1984, a UGM, motivada pela perspectiva de aumento da passagem do ônibus, no dia 13 de janeiro de 1985, um domingo, impediu, com barricadas nos principais pontos de acesso à região norte, a circulação dos ônibus naquela região da cidade. E, não conseguindo, apesar do feito, abrir negociações 
com o poder público local, voltou, no dia seguinte, uma segunda-feira, novamente a interromper a circulação dos coletivos, o que, por ocorrer num dia de trabalho, causou maiores transtornos à vida da cidade. Mas, como era de esperar, ao invés de se abrirem negociações, e diferentemente do que ocorreu domingo, a reação do poder local foi repressiva, agindo a polícia violentamente para desobstruir as entradas de acesso à região norte, num conflito que resultou na detenção e indiciamento de alguns militantes e que levou outros ao hospital, em conseqüência da ação policial.

Para não alongarmos muito a narrativa da rememoração desse movimento, cabe dizer que, apesar da repressão sofrida, o movimento dos transportes, naquela oportunidade, obteve, além da suspensão do reajuste da tarifa, que passaria a ficar condicionada ao reajuste do salário mínimo, a criação de uma comissão, formada por concessionária, usuários e poder público, e também por uma representação da Câmara Municipal, que passaria a ter a responsabilidade de definir uma política de transportes mais adequada à cidade, bem como o valor da tarifa. Era a primeira vez que se criava uma comissão com a participação dos setores populares para a discussão das políticas públicas.

Poderíamos descrever outros movimentos que fizeram parte desse processo que marcou a mudança nas relações entre o poder público e a população local, e que foram coroados com a criação de novos espaços de interlocução. Mas penso que essa breve rememoração das lutas empreendidas pela UGM é suficiente como ilustração do significado dos movimentos populares locais na vida da cidade de Londrina, nos anos 80, ao mesmo tempo que indicativa da importância dos movimentos no processo de redemocratização da vida brasileira nos anos recentes.

O que parece ter ficado evidente com esse processo de demandas sociais e políticas, vivido pelo país nos anos 80 , foi a emergência de princípios e valores democráticos e sua vivência nas distintas dimensões da vida social e política da sociedade brasileira — do interior da vida doméstica à praça pública, valores e princípios que seriam consagrados na Constituição de 1988 - um momento de fundação de uma nova sociedade, então acolhedora da participação popular nas decisões de interesse público. Isso ficou registrado com a adoção dos novos institutos de ação democrática, como o plebiscito, o referendum e a iniciativa popular na proposição de leis, mediante determinado número de 
assinaturas. A esses dispositivos democráticos, que correspondem a assegurar de forma legal o princípio da participação popular na gestão pública, tornando a cidadania menos passiva da ação estatal (Benevides, 1991), somaram-se as práticas participativas nos governos locais práticas asseguradas pelas constituições federal e estaduais e pelas leis orgânicas dos municípios - através de fóruns, conferências e conselhos setoriais que passaram, em muitos municípios, a ser instâncias de definições e deliberações das políticas públicas, conforme exemplificado anteriormente, com relação ao setor da saúde em Londrina. ${ }^{8}$

Ora, esse saldo, ou melhor, essas conquistas dos movimentos sociais dos anos 80 não podem ser rapidamente esquecidas ou simplesmente ignoradas; elas correspondem à afirmação de valores democráticos como norteadores da vida social e política, a partir dos quais a sociedade se abre ao reconhecimento da alteridade. Trata-se, pois, do saldo de uma experiência inestimável e única que não pode ser compreendida unicamente tendo por foco o período autoritário, no qual os valores democráticos emergiram justamente como resistência à falta de democracia vivida naquele momento. Negar a afirmação das conquistas democráticas é abdicar de um passado de lutas, é perder a oportunidade de prática e, portanto, de afirmação de uma nova cultura política que, mais do que acomodar-se à atitude de subordinação em que a sociedade civil se colocou em relação à política no Brasil, aponta um caminho de construção da convivência social e política da sociedade brasileira, e que, evidentemente, não se trata de um caminho de integração social às avessas, em que se escamoteia o conflito, mas um caminho onde seja possível despertar o civismo, que transforma atores em sujeitos e, portanto, capazes de um sentimento de cidadania, de verdadeira cidadania, ou seja, de co-responsabilidade no assegurar um espaço comum de existência de sujeitos diversos, sem o qual não há a mínima plausibilidade da existência de uma sociedade democrática.

\section{AFINAL, QUAL A NOVIDADE DOS MOVIMENTOS DOS ANOS 70-80?}

Mas, avaliar corretamente o significado da experiência recente dos movimentos sociais e o seu legado para o futuro é uma questão difícil, especialmente porque, em regra, busca-se o significado do legado

Rev. Mediações, Londrina, v. 5, n. 1, p. 79-94, jan.jjun. 2000 
dessa experiência nas conquistas sociais imediatas, indicadas por dados estatísticos socioeconômicos que, notoriamente, são desabonadores da experiência recente. Por exemplo, tomando tais indicadores por base, 0 que se tem dito é que a década de 80 foi um avanço do ponto de vista político, mas um retrocesso do ponto de vista econômico, uma vez que junto com o aumento da participação nas decisões políticas houve o aumento da concentração da renda e o agravamento das questões sociais, o que é correto, mas desfoca o objetivo realmente significativo da experiência recente, vivida através dos movimentos sociais.

Creio que é o sentido propriamente político assumido pelos movimentos o que torna relevante o seu legado. E este consiste, fundamentalmente, na emergência de sujeitos sociais e políticos que nasceram justamente a partir do discurso e da ação autônomos, o que não significa, é evidente, a desconexão com um processo histórico que antecede os anos de regime militar, ao contrário, é perfeitamente congruente com ele, como um seu desdobramento, como forma alternativa que nasce da experiência da fase imediatamente anterior, mas sem guardar, em relação a ela, nenhum vínculo de dependência ou de determinação previamente esperada.

Os movimentos dos anos 70-80 fizeram mais do que resistir ao regime militar e protagonizar um processo de transição para um regime democrático, conforme ilustrado aqui, com a breve narrativa da trajetória de um movimento popular de Londrina. E essa especificidade dos movimentos dessa fase da vida brasileira torna-se mais compreensível quando pensada em contraponto aos movimentos que se desenvolveram na fase que antecede ao golpe de 64.

Um dos indicadores da novidade dos movimentos dos anos 7080 era que eles surgiram nos locais de moradia e nos locais de trabalho organizados e mobilizados à revelia do Estado e da tutela das instituições e dos correspondentes canais tradicionais de manifestação social e política, como os partidos e os sindicatos. E esse era um dado novo que distinguia os movimentos daqueles anos como "novos movimentos sociais", 9 diferenciando-os dos movimentos de antes de 64, cuja característica marcante era a submissão ao controle político das instituições tradicionais.

Nesse sentido, o acolhimento dos movimentos dos anos 70-80 vinha ancorado na crítica aos movimentos da fase anterior ao golpe militar, cuja sujeição à tutela dos partidos e dos sindicatos, bem como à 
manipulação do poder público instituído, através de suas políticas populistas, era tida como a razão do fracasso dos trabalhadores e dos setores populares, de modo geral, em resistir à reação ao processo revolucionário que se desenhava e que foi interrompido pelo golpe. (Telles, 1987)

Um outro indicador da novidade era que os movimentos anunciavam a presença de novos atores no espaço público, o chamado povo simples da periferia que se organizava (e se organiza) em torno de reivindicações por melhores condições de vida em meio urbano. E era evidente que havia nisso algo novo, ou seja, além de o próprio povo simples passar a ter vez e voz, ser visto e ouvido, havia uma valorização da vida social como espaço de manifestação política. A ação política contestatória, do povo simples da periferia, em lugares tidos como exclusivos do espaço social, correspondia a uma politização da vida social.

A presença dos setores populares no espaço público como atores políticos, como sujeitos e não apenas como objeto das políticas públicas era, de fato, uma novidade. O dado novo aqui é o fato de, em primeiro lugar, questionar a noção de atraso e impotência, de incapacidade de auto-organização que, até então, se imputava às classes populares; em segundo, o fato de desmontar o argumento das elites dominantes que, baseado na falsa afirmação de incapacidade dos setores populares, justificava a necessidade que têm esses setores de ser tutelados pelas elites para a construção democrática. Um argumento autoritário, evidentemente, do qual sempre se valeu a classe dominante brasileira para a manutenção e defesa dos seus interesses, e que, portanto, era plenamente refutado pelos movimentos populares daqueles anos. Nesse sentido, o que se evidenciava era a politização da vida social, pondo em questão o caráter tecnoburocrático da gestão pública realizada nos governos militares. ${ }^{10}$

Esses indicadores que anunciavam os "novos movimentos sociais" - a manifestação política fora dos canais consagrados e a presença ativa da população organizada da periferia sem a tutela das instituições tradicionais - possibilitavam considerá-los como autônomos; porque se organizavam a partir de questões comuns do cotidiano da periferia e longe do alcance de qualquer modelo de ação e/ ou discurso previamente delimitado e supostamente revolucionário; não obstante, ou certamente porque autônomos, os movimentos e suas lutas lograram fazer emergir o sentido político da vida social, inscrevendo na 
vida pública da sociedade brasileira sujeitos antes tidos como meros objetos das políticas oficiais.

Essa noção de autonomia foi positivamente considerada como característica fundamental desses "novos movimentos"; movimentos que se propõem como portadores do novo, pelo que se incluía, também, o caráter democrático de sua organização interna, valorizando-se as decisões coletivas e não-hierarquizadas dos participantes dos movimentos.

Pois bem, são esses valores de uma cultura política renovada que nos parecem fundamentais à construção da democracia e que nos foram deixados pelos movimentos sociais dos anos 70-80. Renunciar a tais valores ou ignorá-los em face da urgência das soluções que reclamam as questões sociais é facilitar falsas soluções, imediatistas e, igualmente, autoritárias como têm sido há séculos as respostas dadas aos problemas pela sociedade brasileira, como se o encaminhamento ou mesmo a solução das questões sociais fossem obstaculizadas pela participação democrática.

Ora, não podemos nos fazer de inocentes, pois estamos mais do que "escolados" que só temos a perder com as soluções autoritárias; vejam, agora, o governo de FHC, revelando o máximo de requinte em cinismo e prepotência autoritários para impor ao país políticas que se têm revelado negativas à maioria do seu povo, num processo incrível de manipulação da população através da veiculação de uma imagem de governante culto e civilizado, e, supostamente, por isso mesmo, capaz de decidir por sua própria cabeça, o que só é possível pelo cerceamento da participação ativa da sociedade civil organizada (o que esse governo buscou sistematicamente assegurar desde o início do primeiro mandato, quando repreendeu com violência o movimento dos petroleiros, então motivado por descumprimento de acordo feito anteriormente com o próprio governo).

O que aqui se quer dizer é que não basta substituir esse governo por outro, como um mero procedimento democrático de alternância de poder, é preciso antes radicalizar a democracia, resgatar a política como prática e ação que se desenhou nos anos recentes, pois renunciar aos procedimentos democráticos participativos tende a permitir soluções encabeçadas por "salvadores da pátria", impostas autoritariamente e, por isso mesmo, despolitizadas. E isso é o que de mais grave poderíamos ter, porque seria a negação de um processo de lutas que criou novos 
sujeitos sociais e lhes assegurou espaços de participação social e política para além da democracia representativa.

Fica claro, portanto, e é o que aqui se defende, que é preciso assegurarmos os espaços de interlocução públicos, nos seus diversos níveis de decisões, espaços em que se abriga a pluralidade dos atores, em que todos são vistos e ouvidos, espaço de crítica, com visibilidade necessária para a formação da opinião pública, dos critérios de julgamento que sejam válidos para a sociedade fazer suas escolhas, escolher os seus caminhos, de forma que a democracia, assim concebida, possa ser, de fato, efetiva, porque fundada na soberania popular. Esse é o caminho democraticamente válido para se construir um país menos injusto, um país de cidadão ativos.

\section{NOTAS}

1 Entre muitos: Gohn (1997), ressalvando que a autora credita o refluxo dos movimentos ao fato de terem surgido novos atores, como as ONGs e/ou o chamado terceiro setor, com novas formas de participação; dom Pedro Casaldáliga que, em entrevista à Revista Adusp, de junho de 1997, afirma ter havido uma diminuição dos movimentos sociais nos anos 90. (Casaldáliga, 1997) Tais afirmações, no entanto, não têm sido acompanhadas de dados que as comprovem. Nesse sentido, não é seguro afirmar nem negar a diminuição dos movimentos. Porém, é certo que houve uma diminuição da visibilidade dos movimentos nos anos 90 .

2 Refiro-me aos conselhos comunitários e municipais, às conferências setoriais e fóruns que, criados com muito entusiasmo no final dos anos 80 e início dos 90 , muitos já deixaram de existir e outros têm participação reduzida e meramente formal.

3 Talvez não se possa creditar a ninguém, com exclusividade, a mudança ocorrida na forma de mobilizar e organizar os setores populares, mas, certamente, o rompimento com a forma centralizada, vanguardista, característica dos movimentos controlados pelos partidos de esquerda, em regra, foi logrado pela Igreja Católica através do seu segmento da Teologia da Libertação, cujo método: ver, julgar, agir, à luz dos textos bíblicos deu uma outra dinâmica interna aos movimentos, com mais criatividade, mais participação e valorização das iniciativas dos militantes, a partir de uma estrutura hierárquica mais fluida e menos verticalizada.

4 Paoli (1989) chama a atenção para essa nova noção de cidadania que nos legaram os movimentos sociais dos anos 70-80.

5 Lefort (1987), em "Direitos do homem e política", ao destacar o significado político dos direitos faz a crítica ao texto de Marx, A questảo judaica.

${ }^{6} \mathrm{O}$ fato de o Conselho de Saúde estar em pleno funcionamento não significa que esteja funcionando bem. A propósito, a aceitação de uma maior participação popular na administração pública não é vista com bons olhos pelas forças conservadoras nem por aquelas que muitas vezes se apresentam como progressistas; de um modo geral ainda estamos aprendendo a fazer política através de processos mais transparentes. E, apenas para registro, como ilustração da dificuldade em se consolidar o processo participativo 
como próprio de uma dada cultura política, as duas últimas conferências (1995 e 1997) deliberaram (a segunda reafirmando a deliberação da primeira) pela ampliação da representação no Conselho Municipal de Saúde, mas, até então, o Executivo municipal recusou-se a acolher a deliberação da conferência. Recusa que está afeta, evidentemente, à possibilidade da perda de controle sobre o Conselho, por parte do Executivo.

7 Uma análise da trajetória dos movimentos populares de Londrina e do lugar reservado aos setores populares na cidade é feita por Silveira (1997). Uma análise específica da UGM é feita por Colito (1987).

8 Embora muitos conselhos sejam criados com função deliberativa, parece haver controvérsia sobre esse entendimento, uma vez que haveria conflito de competência com a Câmara Municipal e com o próprio Executivo. Todavia, embora se ressalte o aspecto legal, esta é fundamentalmente uma questão política.

"A denominação de "novos movimentos sociais" aos movimentos surgidos no Brasil assim como na América Latina, nos anos 70-80, se deve por se distinguirem dos movimentos de antes de 64, e não por uma indevida importação do conceito, que só teria sentido para os movimentos dos países desenvolvidos. Se nos países desenvolvidos os movimentos foram distinguidos como novos por trazerem novas problemáticas, como a feminista, a ecológica, a pacifista, entre nós tais questões não estão ausentes, mas não são por elas que aqui se distinguem os movimentos populares dos anos 70-80 como "novos", mas, fundamentalmente, porque eles se mostraram, no discurso e na ação, como movimentos autônomos. O livro organizado por Ilse Scherer-Warren e Paulo J. Krischke, Uma revolução no cotidiano? Os novos movimentos sociais na América do Sul, por exemplo, traz excelentes artigos que enriquecem a discussão sobre os novos movimentos sociais.

${ }^{10}$ Uma análise brilhante sobre a discurso dominante que desqualifica a capacidade de autodeterminação dos setores populares é feita por Paoli, Sader e Telles (1983) e por Sader \& Paoli (1988).

\section{REFERÊNCIAS BIBLIOGRÁFICAS}

BENEVIDES, Maria Victória de M. A cidadania ativa. São Paulo: Ática, 1991.

CASALDÁlıIGA, Pedro, Dom. Santo guerreiro. Revista Adusp, Associação dos Docentes da USP, Seção Sindical da Andes - SN -n.10, p.6-14, jun. 1997. Entrevista concedida a Marcos Cripa.

CASTEL, Robert. As metamorfoses da questão social. Petrópolis: Vozes, 1998.

COLITO, Maria C.E. As duas realidades presentes em um movimento social popular. São Paulo, 1987. Dissertação (Mestrado em Serviço Social) - Pontifícia Universidade Católica de São Paulo.

GOHN, Maria da Glória. Os sem-terra, ONGs e cidadania. São Paulo: Cortez, 1997.

LEFORT, Claude. Os direitos do homem e política. In: $A$ invenção democrática. Os limites do totalitarismo. São Paulo: Brasiliense, 1987. p.37-69.

PAOLI, Maria Célia. Trabalhadores e cidadania, experiência do mundo público na história do Brasil moderno. USP Estudos Avançados, v.3, n.7, p.40-66, set./dez. 1989.

; SADER, Éder; TELLES, Vera da Silva. Pensando a classe operária: os trabalhadores

Rev. Mediaçóes, Londrina, v. 5, n. 1, p. 79-94, jan./jun. 2000 
sujeitos ao imaginário acadêmico. Revista Brasileira de História, n.6, p.129-149, set. 1983.

SADER, Eder \& PAOLI, Maria Célia. Sobre "classes populares" no pensamento sociológico brasileiro (Notas de leituras sobre acontecimentos recentes). In: CARDOSO, Ruth (org.) A aventura antropológica, teoria e pesquisa. São Paulo: Paz e Terra, 1988.

SCHERER-WARREN, Ilse \& KRISCHKE, Paulo J. (orgs.) Uma revolução no cotidiano? Os novos movimentos sociais na América do Sul. São Paulo: Brasiliense, 1987.

SLVEIRA, Ricardo de Jesus. As associações de moradores e a construção do espaço público: um exercício de cidadania. São Paulo, 1997. Tese (Doutorado em Sociologia)

- Universidade de São Paulo.

TELLES, Vera da Silva. Movimentos sociais. Reflexões sobre a experiência dos anos 70. In: SCHERER-WARREN, Ilse \& KRISCHKE, Paulo J. (orgs.) Uma revolução no cotidiano? Os novos movimentos sociais na América do Sul. São Paulo: Brasiliense, 1987.

\section{RESUMO}

O objetivo do artigo é destacar a importância da reflexão sobre a herança deixada pelos movimentos sociais dos anos 70 e 80 , no Brasil, para o enfrentamento dos problemas de exclusão social e política impostos pela política neoliberal adotada pelos governos brasileiros na última década. A análise se vale, brevemente, da experiência dos movimentos populares de Londrina.

Palavras-chave: movimentos sociais; cidadania; espaço público.

\section{ABSTRAT}

The aim of this article is to emphasize the importance of reflecting upon the heritage left by the social movements of the 70's and 80 's in Brazil, as a way of dealing with the problems social and political exclusion posed by the governmental neoliberal politics imposed in the last decade. The analysis is been worth, shortly, of the experience of the popular movements of Londrina.

Key words: social movements; citizenship; public spaces.

Ricardo de Jesus Silveira é professor de Sociologia do Departamento de Ciências Sociais da UEL. 